\title{
Study Concerning the Influence of the Grinding Percentage on Some Electrical Properties of PA 6.6, POM and ABS by Methods for Determining Relative Permittivity and the Dielectric Dissipation Factor
}

\author{
OVIDIU CONSTANTIN NOVAC*, GHEORGHE RADU EMIL MARIES, DAN CHIRA, MIHAELA NOVAC \\ University of Oradea, 1 Universitãii Str., 410087, Oradea, Romania
}

\begin{abstract}
This paper presents the influence of the grinding percentage on some electrical properties, when the process of injection is used in the production of technical commodities, made of polyamide 6.6 (PA 6.6), polyoxymethylene (POM) and acrylonitrile butadiene styrene (ABS), for different industries. The specimens produced had the following compositions: new material 100\%, new material $80 \%+$ grinding $20 \%$, new material 60\% + grinding 40\%, new material 40\% + grinding 60\%, new material 20\% + grinding $80 \%$ and $100 \%$ grinding. The measurement of the electrical properties was carried out using the methods for the determination of relative permittivity and of the dielectric dissipation factor, with the method of zero by Schering bridge. It was found that increasing the percentage of grinding in samples, from $0 \%$ to $100 \%$, determined a slight increase in the values of relative permittivity at all three polymers tested and the increase of measurement frequencies for acrylonitrile butadiene styrene and polyoxymethylene led to insignificant changes in the values of relative permittivity, while in the case of polyamide, increasing the measurement frequency led to a slight decrease in the values of relative permittivity. It was also found that increasing the proportion of grinding in the specimens, from $0 \%$ to $100 \%$, determined a slight increase in the values of the dielectric dissipation factor in the case of polyamide and polyoxymethylene, while in the case of acrylonitrile butadiene styrene increasing the percentage of grinding in the samples resulted in insignificant changes. The increase in the measurement frequencies for the three tested polymers resulted in a decrease in the values of the dielectric dissipation factor.
\end{abstract}

Keywords: percentage of grinding, polyamide 6.6 (PA 6.6), polyoxymethylene (POM), acrylonitrile butadiene styrene, $(A B S)$ relative permittivity, dielectric dissipation factor

Among the industries that use plastics, one can mention: electronic and electro technical industry, electric goods industry, automotive industry, engineering industry, toyindustry, tourism and sports industry [1], photographic industry, medical industry, and packaging industry. The macromolecular compounds that are most widely-used in the manufacturing of various types of products in the industries mentioned above are: polyvinyl chloride, polyethylene, polypropylene, polyamides, polycarbonates, thermoplastic polyurethanes, polyoxymethilene, polymethylmethacrylate, methyl cellulose acetate, acrylonitrile butadiene styrene, etc. Injection is most widely used technology for turning such macromolecular compounds into finished products.

Polyamides are semi-crystalline macromolecular compounds with a wide range of use in various technical fields, both as non-reinforced polyamide and as polyamide reinforced with glass fiber, carbon fiber, molybdenum disulfide, silica, metal fibers [2,3]. Polyamides are materials with good mechanical strength, moderate stiffness, which increases when they are reinforced with glass fibers. They have good dimensional stability, are resistant to shock, operation at low temperatures, compression and abrasion, especially when they are reinforced with molybdenum disulfide or graphite. They are hard materials, which remain hard and tough and show no noticeable changes when exposed to heat, (temperatures up to $80-90^{\circ} \mathrm{C}$ ) [4,5]. They adhere well to steel, can be processed easily and have a pleasant surface. They resist well in salt water, are stable to oil, hydrocarbons, varnish, weak bases, esters, ethers, alcohols and automotive fuel. All these properties recommend them to be used in the manufacture of various technical articles. Uses: automotive industry (frames, gasoline tanks, water tanks, brake fluid reservoir, bushings, pins, flexible wiring, floats for carburetor, air circulation systems, fans, etc.), electrical industry (connectors, enclosures for drills), engineering industry (bandages for wheels, friction elements, gears), household devices (juicer, blender, handles of cutlery, heads for hammers), industry of tourism and sport (ski boots, skates, tents, climbing ropes, helmets, soles for athletics shoes).

Polyoxymethilenes, sometimes referred to as polyacetals, are highly crystalline polymers, based on a regular structure of methylene ether. They are opaque polymers, with a low melting range. Slight absorption of water affects neither their mechanical and electrical properties, nor their dimensional stability. Products made from POM can be used in a broad temperature range ($\left.50^{\circ} \mathrm{C} /+90^{\circ} \mathrm{C}\right)$. They present a series of mechanical properties that make them highly performant and even good at replacing metal. They are resistant to cyclic loading, shock, fatigue, friction and wear. They have good resistance to many organic chemicals (aldehydes, esters, ethers, herbicides, insecticides, fertilizers) and are sensitive to oxidizing acids and strong bases. Hydrocarbons may plasticize POM and lead to lower mechanical strength. Uses: engineering industry (gears, racks, valves, elements of chain, parts for conveyor belts, screws, spacers, rods,

*email: onovac@uoradea.ro; Phone: (+40)726301644 
gears), automotive industry (gears, housings, guides, active parts of the oil or diesel pump, floats, valves), domestic appliances (housings for vacuum cleaners, mixers, coffee makers, fittings for pneumatic systems), the photographic industry (frames for cameras), the industry of sports products (gears for gear exchangers at bicycles, ski bindings, elements for roller skates).

$A B S$ is rigid, tough and shock resistant. It is resistant to wear, abrasion, has good dimensional stability in a wide temperature range, unlimited color possibilities, light training [6] and is a good electrical insulator. It is resistant to acids, weak bases and it is unstable to esters, ketones, ethers and gasoline. Uses: electrical industry (housings for computers, monitors, television sets, tape recorders, audio systems), household goods (parts in refrigerators, mixers, coffee makers), automotive industry (parts of the seats, bumpers, enclosures for electrical and electronic assemblies, which are attached above the car boot).

A topical issue relating to the processing of thermoplastic polymers by injection is waste recovery. Such waste appears in various forms: injection piping system, incomplete parts, parts with burrs or other parts showing manufacturing defects. Their reintroduction in the production process (as grinding) has been practiced for a long time, leading to increased productivity. Grinding can also be introduced in the production process when mixed with new material (material that has never been processed by injection) or it can simply be injected separately (only grinding).

During the processing of thermoplastic polymers by injection, the characteristics of products are influenced by the temperature of the material, by the pressure whereby the flowable material fills the mold cavity, by the mold temperature [7-11], and the proportion of grinding reused and mixed with new material [12,13]. In recent years a series of studies have been published on the mechanical and electrical behavior of different types of polymers in different conditions of stress [14-29].

This paper aims to analyze the variation of some electrical properties, depending on changes in the percentage of grinding (polymer thermoformed by injection one time only), as present in specimens, and the measuring frequency, using methods for determining relative permittivity and the dielectric dissipation factor, and the method of zero by Schering bridge for PA 6.6 TECHNYL AR218V30 Blak polyamide type, polyoxymethylene POM EUROTAL C9NAT and ABS MAGNUM 3453, materials used, in this case, for the manufacturing of technical commodities.

\section{Experimental part}

For the production of specimens, the following materials were used: the polyamide of the type PA 6.6 TECHNYL AR218V30 Blak, the polyoxymethylene POM EUROTAL C 9 NAT and the acrylonitrile butadiene styrene ABS MAGNUM 3453, using an injection machine ENGEL CC 100 Type ES $80 / 50 \mathrm{HL}$, manufactured in 1995 (fig. 1).

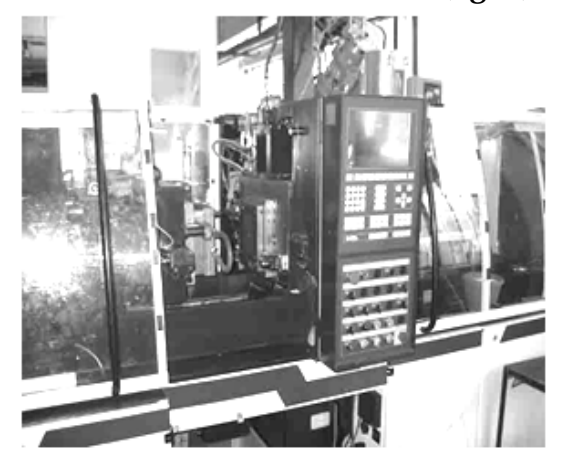

Fig.1. ENGEL CC 100 Type ES 80/50

$\mathrm{HL}$ injection machine
Six samples for each type of material were injected, samples with a variable content, as shown in table 1.

Table 1

THE CONTENT OF SAMPLES TESTED

\begin{tabular}{|c|c|}
\hline Sample & Sample content \\
\hline Sample 1 & $100 \%$ new material \\
\hline Sample 2 & $80 \%$ new material $+20 \%$ grinding \\
\hline Sample 3 & $60 \%$ new material $+40 \%$ grinding \\
\hline Sample 4 & $40 \%$ new material $+60 \%$ grinding \\
\hline Sample 5 & $20 \%$ new material $+80 \%$ grinding \\
\hline Sample 6 & $100 \%$ grinding \\
\hline
\end{tabular}

Injecting the polyamide type PA 6.6 TECHNYL AR218V30 Blak was done in accordance with the following parameters: injection temperature $300^{\circ} \mathrm{C}$, mold temperature $85^{\circ} \mathrm{C}$, injection pressure of 370 bar, further pressure $300 \mathrm{bar}$, injection rate of $100 \mathrm{~mm} / \mathrm{s}$, cycle time of injection $26 \mathrm{~s}$ and the mold cooling time of $10 \mathrm{~s}$, injection time of $0.94 \mathrm{~s}$ and the subsequent pressure holding time of $3 \mathrm{~s}$. While injecting the six samples, the injection parameters were kept constant.

Injecting the polyoxymethylene-type POM EUROTAL C9 NAT was done in accordance with the following parameters: injection temperature $200^{\circ} \mathrm{C}$, temperature of the mold $50^{\circ} \mathrm{C}$, injection pressure $1000 \mathrm{bar}$, further pressure 300 bar, injection rate $20 \mathrm{~mm} / \mathrm{s}$, the cycle time of injection $32.60 \mathrm{~s}$, cooling time in the mold $15 \mathrm{~s}$ and the injection time of $4.2 \mathrm{~s}$ and the subsequent pressure holding time of $5 \mathrm{~s}$. While injecting the six samples, the injection parameters were kept constant.

Injecting the acrylonitrile butadiene styrene ABS MAGNUM 3453 was done in accordance with the following parameters: injection temperature $230^{\circ} \mathrm{C}$, temperature of the mold $50^{\circ} \mathrm{C}$ injection pressure 800 bar, further pressure 300 bar, injection rate $30 \mathrm{~mm} / \mathrm{s}$, the cycle time for injection $43 \mathrm{~s}$ and the mold cooling time of $20 \mathrm{~s}$, injection time of $2.87 \mathrm{~s}$ and the subsequent pressure holding time of $6 \mathrm{~s}$. While injecting the six samples, the injection parameters were kept constant.

All samples injected were subject to the following types of electrical measurements: determination of relative permittivity and of the dielectric dissipation factor. All tests were performed at room temperature, in the laboratories of InstitutSuperieur d'Electronique et du Numerique (ISEN), of the Catholic University of Lille, France and in the new laboratories of ISEN - Urban Wood, Lille, France.

Determining the relative permittivity and the dielectric dissipation factor, using the method of zero by Schering bridge

To determine relative permittivity and the dielectric dissipation factor, the method of zero was used. This method can be used at measurement frequencies up to $100 \mathrm{kHz}$. For determination, a Schering bridge, balanced by adjusting one of the arms, both with and without samples, was used. The values of: $200 \mathrm{~Hz}, 500 \mathrm{~Hz}, 1000$ $\mathrm{Hz}, 5000 \mathrm{~Hz}, 10000 \mathrm{~Hz}$ and $20000 \mathrm{~Hz}$ were used as measurement frequencies.

The Schering bridge shown in figure 2 is a four-arm bridge, in which two arms are capacitive, $C_{N}$ (without 


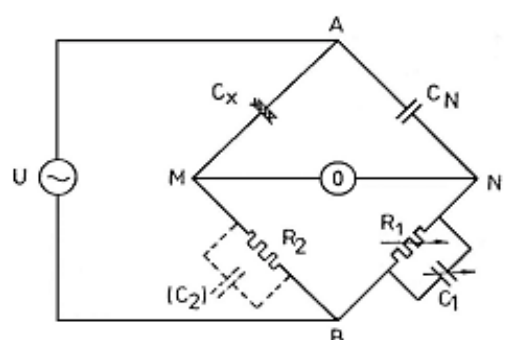

Fig.2. The Schering bridge used for determining the $\mathrm{C}_{x}$ capacity of the sample
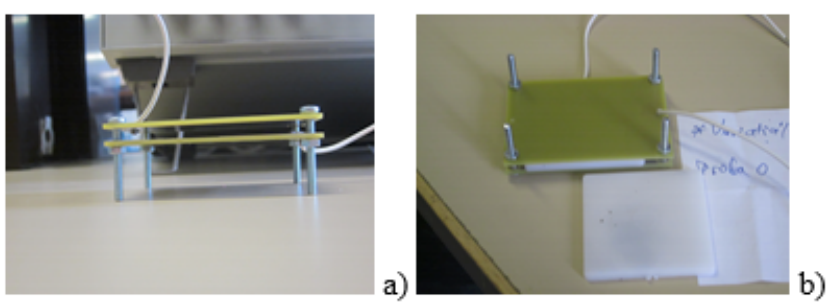

Fig.3. Measuring device: a) without specimen; b) the specimen placed between the terminals of the device

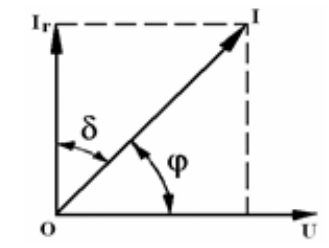

Fig.4. The phase shift between current and voltage for a capacitor

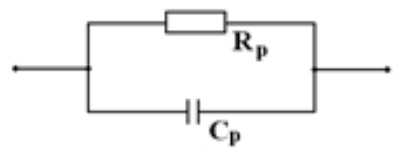

Fig.5. The equivalent diagram in parallel for a capacitor with losses

losses) and $C_{x}$, and two, $R_{1}$ and $R_{2}$ are resistive. Resistance $R_{1}$, variable is opposed to the unknown $C_{x}$ (the capacity of the sample), this resistance being shunted with capacity $\mathrm{C}_{1} . \mathrm{C}_{\mathrm{N}}$ is the standard capacity of the bridge.

In order to determine relative permittivity and the dielectric dissipation factor we used a device with two terminals between which we placed the specimen (fig 3).

Relative permittivity $\left(\varepsilon_{r}\right)$ of a dielectric environment is calculated using the formula:

$$
\varepsilon_{r}=\varepsilon / \varepsilon_{0}
$$

where:

$\varepsilon$ is the absolute permittivity of that environment,

$\varepsilon_{0}$ is the permittivity of the vacuum

The relative permittivity of an insulating material is determined experimentally by the relationship:

$$
\varepsilon_{r}=C_{X} / C_{0}
$$

where:

$C_{x}$ is the capacity of a capacitor in which the space between and around the electrodes is wholly and exclusively filled with insulating material,

$C_{0}$ is the capacity of the same arrangement of electrodes in a vacuum.

The relative permittivity of free $\mathrm{CO}_{2}$ dry air, at normal atmospheric pressure, is equal to the value of 1.00053 . In the experimental measurements performed, we used the capacity of the electrodes in air device $C_{\text {par }}$ instead of the capacity in vacuum $C_{0}$ to determine with sufficient precision the relative permittivity $\varepsilon$.

We determined the value of ${ }^{p}$ the device parasitic capacitance $C_{p a r}$ with the relationship:

where:

$$
C_{\text {par }}=\varepsilon_{0} \cdot S / d
$$

Fig.6. HP device Model 4276A LCZ meter, for measuring the components of the circuit

$\varepsilon$ is the permittivity of the vacuum, $\varepsilon_{0}=1 / 4 \pi \times 9 \times 10^{9}$ $=0.08854,[\mathrm{pF} / \mathrm{cm}]$

$S$ is the area of the terminal of the device, $S=37.25 \mathrm{~cm}^{2}$ $d$ is the distance between the terminals of the device, $\mathrm{d}=0.4 \mathrm{~cm}$

The value obtained for $\mathrm{Cpar}=8.25 \mathrm{pF}$

The value of the $C_{x}$ capacity is calculated using the following equation:

where:

$$
C_{X}=\varepsilon_{\text {mas }} \cdot S / d
$$

$\varepsilon_{\text {mas }}$ is the permittivity of the specimen,

$S$ is the area of the terminal of the device, $S=37.25 \mathrm{~cm}^{2}$

$d$ is the distance between the terminals of the device, with the specimen between terminals, $d=0.4 \mathrm{~cm}$

Finally, relative permittivity is calculated using the relation:

$$
\varepsilon_{r}=\varepsilon_{\text {mas }} / \varepsilon_{0}=\left(C_{X} \cdot d / S\right) /\left(C_{\text {par }} \cdot d / S\right)=C_{X} / C_{\text {par }}
$$

The dielectric loss angle, $\delta$, of an insulating material is the angle complementary to the phase angle $(\varphi)$ between the voltage applied and the current, respectively, when the dielectric of the capacitor is made exclusively from this material (fig.4).

Figure 5 shows the equivalent diagram in parallel for a capacitor with losses.

The tangent of the dielectric loss angle, $\operatorname{tg} \delta$, of an insulating material, is the size expressing the result of measuring the dielectric loss angle $\delta$ of this material.

To calculate the dielectric loss angle tangent $\operatorname{tg} \delta$, we used the relation for parallel representation:

$$
\operatorname{tg} \delta=1 / \omega C_{p} R_{p}=G_{p} / \omega \cdot C_{p}=G_{p} / 2 \pi f_{\text {mas }} \cdot C_{p}
$$

where:

$f_{\text {is }}$ is the measurement frequency, $(200 \mathrm{~Hz}, 500 \mathrm{~Hz}, 1000$ $\mathrm{Hz}, 5000 \mathrm{~Hz}, 10000 \mathrm{~Hz}$ and $20000 \mathrm{~Hz}$ )

$C p$ is the capacity for the parallel equivalent circuit, [F] $G p$ is conductance (the reverse physical size of electrical resistance, $G p=1 / R p)$, for the equivalent parallel circuit [S].

Both values, $C p$ and $G p$ are read using a HewlettPackard Model 4276A LCZ Meter (fig. 6). HP Agilent 4276A is a tool for measuring the impedance for general use, designed for the measurement circuit components, such as capacitors and inductors, using frequency. The device feeds the Schering bridge with a signal of a certain frequency and the two displays of the device show the values of $\mathrm{Cp}$ (display A) and $\mathrm{Gp}$ (display B). The values are obtained by the instantaneous reading of the values indicated by the device (reading the values on the device was made no later than is from pushing the buttons).

Measuring $\mathrm{C}_{\mathrm{x}}$ capacity was made by balancing the Schering bridge and by adjusting the resistance value $R_{1}$ and the value of $C_{1}$ capacity. The measurement was made using an oscilloscope Tektronix model MD03024 (fig. 7).

The Schering bridge was fed (fig.2) in the nodes A and $B$, with a sinusoidal signal $U_{A B}$ with an amplitude of $5 \mathrm{~V}$ and 


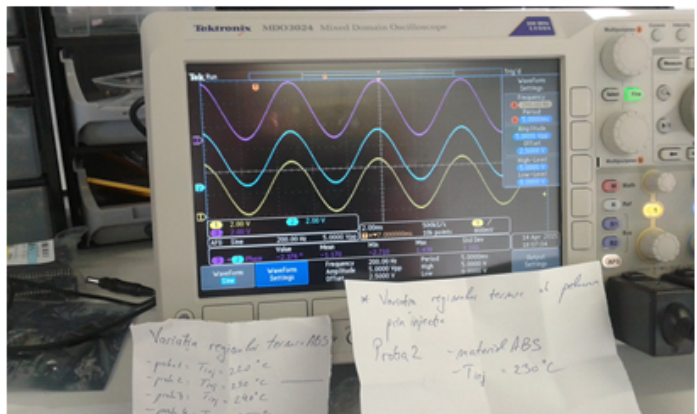

Fig.7.

Oscilloscope

Tektronix

model

MD03024

fmas frequency, as indicated by signal 3, purple, on the display of the oscilloscope (fig.7). The values of the $R_{\text {}}$ variable resistance and $\mathrm{C}$ variable capacity were adjusted so as the current between node $\mathrm{M}$ and node $\mathrm{N}$ would be zero, i.e. the two signals, $U_{M B}$ signal 1 , yellow and $U_{N B}$ signal 2 , blue, would have the same amplitude. Therefore, the equivalent values of capacity $\mathrm{C}_{x}(\mathrm{Cp}$-i Gp) were determined, balancing the bridge by obtaining signals of the same amplitude, as shown in figure 7.

The measurements were made in accordance with the European Standards NFC 26-230: 1970 CEI IEC 60250 [30] on specimens with shapes and dimensions as those show in figure 8.

For the three materials tested (PA 6.6 TECHNYL AR218V30 Blak, POM EUROTAL C9 NAT and ABS MAGNUM 3453) a set of 36 measurements were performed, in order to determine relative permittivity in relation to the proportion of grinding in the samples and the measurement frequency.
4
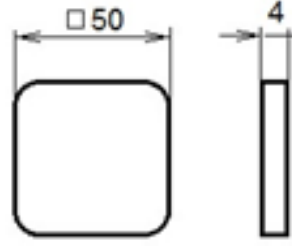

Fig.8. Model sample for determining relative permittivity and the dielectric dissipation factor for the following materials: PA 6.6 TECHNYL AR218V30 Blak, POM EUROTAL C9 NAT and ABS MAGNUM 3453.

Another set of 36 measurements was performed in order to determine the dielectric dissipation factor in relation to the proportion of grinding in the samples and the measurement frequency.

\section{Results and discussions}

After testing the PA 6.6 samples, the following results of relative permittivity were obtained (table 2 ).

For the samples of polyamide tested, it can be observed that increasing the percentage of grinding in samples from 0 to $100 \%$, led to a slight increase in relative permittivity, i.e. reusing grinding in combination with new material leads to a slight increase in the relative permittivity of the manufactured object. This behavior applies to all measurement frequencies. Increasing the measurement frequencies, at each sample tested, leads to a slight decrease in the values of relative permittivity. The highest value of relative permittivity, of 2.2303, was measured at sample 6, at the frequency of $200 \mathrm{~Hz}$, while the lowest value, of 1.5757, was recorded in sample 1, at the frequency of $20000 \mathrm{~Hz}$.

After testing the POM samples, the following results of relative permittivity were obtained (table 3 ).

\begin{tabular}{|c|c|c|c|c|c|c|}
\hline \multirow[t]{2}{*}{ Sample } & \multicolumn{6}{|c|}{ Relative permittivity $\varepsilon_{\mathrm{r}}$ in relation to measurement frequency } \\
\hline & $200 \mathrm{~Hz}$ & $500 \mathrm{~Hz}$ & $1000 \mathrm{~Hz}$ & $5000 \mathrm{~Hz}$ & $10000 \mathrm{~Hz}$ & $20000 \mathrm{~Hz}$ \\
\hline Sample 1 & 1.6727 & 1.6969 & 1.6484 & 1.7090 & 1.6242 & 1.5757 \\
\hline Sample 2 & 1.6969 & 1.7333 & 1.6848 & 1.7184 & 1.6969 & 1.6284 \\
\hline Sample 3 & 1.8181 & 1.7575 & 1.8060 & 1.7212 & 1.6969 & 1.6442 \\
\hline Sample 4 & 1.9636 & 1.9636 & 1.9272 & 1.8424 & 1.8324 & 1.7818 \\
\hline Sample 5 & 2.0121 & 1.9757 & 1.9515 & 1.8787 & 1.8403 & 1.7818 \\
\hline Sample 6 & 2.2303 & 2.2060 & 2.1818 & 2.0727 & 2.0727 & 2.0121 \\
\hline
\end{tabular}

Table 2

THE RELATIVE PERMITTIVITY OF PA 6.6 TECHNYL AR218V30 Blak SAMPLES,

PROCESSED BY INJECTION, IN RELATION TO THE PERCENTAGE OF GRINDING, AT DIFFERENT FREQUENCIES

\begin{tabular}{|c|c|c|c|c|c|c|}
\hline \multirow{2}{*}{ Sample } & \multicolumn{5}{|c|}{ Relative permittivity er in relation to measurement frequency } \\
& $200 \mathrm{~Hz}$ & $500 \mathrm{~Hz}$ & $1000 \mathrm{~Hz}$ & $5000 \mathrm{~Hz}$ & $10000 \mathrm{~Hz}$ & $20000 \mathrm{~Hz}$ \\
\cline { 2 - 7 } & & & & & 2.1454 & 2.1090 \\
\hline Sample 1 & 2.0969 & 2.1333 & 2.1333 & 2.1212 & 2.3757 & 2.3757 \\
\hline Sample 2 & 2.3515 & 2.3515 & 2.3636 & 2.3757 & 2.3757 & 2.3878 \\
\hline Sample 3 & 2.3515 & 2.4000 & 2.4000 & 2.4242 & 2.4242 & 2.4242 \\
\hline Sample 4 & 2.4363 & 2.4242 & 2.4363 & 2.4484 & 2.4484 & 2.4307 \\
\hline Sample 5 & 2.4401 & 2.4302 & 2.4373 & 2.4490 & 2.4504 & \\
\hline Sample 6 & 2.4608 & 2.4484 & 2.4484 & 2.4606 & 2.4527 & 2.4363 \\
\hline
\end{tabular}

Table 3

THE RELATIVE PERMITTIVITY OF POM EUROTAL C9 NAT SAMPLES, PROCESSED BY INJ ECTION, IN RELATION TO THE PERCENTAGE OF GRINDING, AT DIFFERENT FREQUENCIES 


\begin{tabular}{|c|c|c|c|c|c|c|}
\hline \multirow{2}{*}{ Sample } & \multicolumn{5}{|c|}{ Relative permittivity \& in relation to measurement frequency } \\
& $200 \mathrm{~Hz}$ & $500 \mathrm{~Hz}$ & $1000 \mathrm{~Hz}$ & $5000 \mathrm{~Hz}$ & $10000 \mathrm{~Hz}$ & $20000 \mathrm{~Hz}$ \\
\cline { 2 - 7 } & & & & & & \\
\hline Sample 1 & 2.0242 & 2.0000 & 2.0121 & 2.0000 & 2.0242 & 1.9757 \\
\hline Sample 2 & 2.0363 & 2.0363 & 2.0363 & 2.0242 & 2.0363 & 2.0121 \\
\hline Sample 3 & 2.0484 & 2.0442 & 2.0442 & 2.0242 & 2.0363 & 2.0121 \\
\hline Sample 4 & 2.0606 & 2.0606 & 2.0606 & 2.0484 & 2.0484 & 2.0363 \\
\hline Sample 5 & 2.0606 & 2.0707 & 2.0710 & 2.0606 & 2.0606 & 2.0363 \\
\hline Sample 6 & 2.0727 & 2.0716 & 2.0716 & 2.0684 & 2.0606 & 2.0363 \\
\hline
\end{tabular}

Table 4

THE RELATIVE PERMITTIVITY OF ABS MAGNUM 3453SAMPLES, PROCESSED BY INJECTION, IN RELATION TO THE PERCENTAGE OF GRINDING, AT DIFFERENT FREQUENCIES

\begin{tabular}{|c|c|c|c|c|c|c|}
\hline \multirow{2}{*}{ Sample } & \multicolumn{5}{|c|}{ The dielectric dissipation factor tg $\delta$ in relation to the measurement } \\
& \multicolumn{5}{|c|}{ frequency } \\
\cline { 2 - 7 } & $200 \mathrm{~Hz}$ & $500 \mathrm{~Hz}$ & $1000 \mathrm{~Hz}$ & $5000 \mathrm{~Hz}$ & $10000 \mathrm{~Hz}$ & $20000 \mathrm{~Hz}$ \\
\hline Sample 1 & 0.2883 & 0.0682 & 0.0468 & 0.0225 & 0.0356 & 0.0061 \\
\hline Sample 2 & 0.2912 & 0.0877 & 0.0709 & 0.0556 & 0.0444 & 0.0069 \\
\hline Sample 3 & 0.2933 & 0.0989 & 0.0877 & 0.0774 & 0.0646 & 0.0098 \\
\hline Sample 4 & 0.3043 & 0.1233 & 0.1123 & 0.1100 & 0.1022 & 0.0111 \\
\hline Sample 5 & 0.3222 & 0.1422 & 0.1332 & 0.1231 & 0.1033 & 0.0135 \\
\hline Sample 6 & 0.3410 & 0.1667 & 0.1343 & 0.1234 & 0.1113 & 0.0158 \\
\hline
\end{tabular}

Table 5

THE DIELECTRIC DISSIPATION FACTOR FOR THE SAMPLES OF PA 6.6 TECHNYL AR218V30 BLAK, PROCESSED BY INJECTION, IN RELATION TO THE PERCENTAGE OF GRINDING INCLUDED, AT DIFFERENT FREQUENCIES
In the case of the samples of polyoxymethylene tested, we have noticed that increasing the percentage of grinding in samples, from 0 to $100 \%$, leads to a slight increase in relative permittivity, i.e. reusing grinding in combination with new material leads to a slight increase in the relative permittivity of the manufactured object. This behavior applies to all measuring frequencies. Increasing the measurement frequency, at each tested sample, leads to insignificant changes in the values of relative permittivity. The highest value of relative permittivity, of 2.4608, was measured at sample 6 , at the frequency of $200 \mathrm{~Hz}$, while the lowest value, of 2.0969, was recorded in sample 1, at the frequency of $200 \mathrm{~Hz}$.

After testing the ABS samples, the following results for relative permittivity were obtained (table 4).

For the samples of acrylonitrile butadiene styrene tested, it could be observed that increasing the percentage of grinding in samples, from 0 to $100 \%$, leads to a slight increase in relative permittivity, i.e. reusing grinding, in combination with new material, leads to a slight increase in the relative permittivity of the manufactured object. This behavior applies to all measurement frequencies. Increasing measurement frequencies, at each tested sample, leads to insignificant changes in the values of relative permittivity. The highest value of relative permittivity, of 2.0727, was measured at sample 6, at the frequency of $200 \mathrm{~Hz}$, while the lowest value, of 1.9757 , was recorded in sample 1, at the frequency of $20000 \mathrm{~Hz}$.

As a conclusion, it can be argued that increasing the percentage of grinding in samples, from 0 to $100 \%$, leads to a slight increase in the values of the relative permittivity at all three polymers tested. Increasing measurement frequencies for acrylonitrile butadiene styrene and polyoxymethylenes leads to insignificant changes in the values of relative permittivity while increasing measurement frequencies in the case of polyamide leads to a slight decrease in the values of relative permittivity.

After testing the samples of PA 6.6, the following results for the dielectric dissipation factor were obtained (table $5)$.

For the samples of polyamide tested, it can be pointed out that increasing the percentage of grinding in samples, from 0 to $100 \%$, leads to a slight increase in the dielectric dissipation factor, i.e. reusing grinding in combination with new material leads to a slight increase of the dielectric dissipation factor for the manufactured object. This behavior applies to all measurement frequencies. Increasing measurement frequencies, at each sample tested, results in a decrease in the values of the dielectric dissipation factor. The highest value of the dielectric dissipation factor, of 0.3410 , was measured at sample 6 , at the frequency of $200 \mathrm{~Hz}$, while the lowest value, of 


\begin{tabular}{|c|c|c|c|c|c|c|}
\hline \multirow{2}{*}{ Sample } & \multicolumn{5}{|l|}{ The dielectric dissipation factor tg $\delta$ in relation to the measurement frequency } \\
\cline { 2 - 7 } & $200 \mathrm{~Hz}$ & $500 \mathrm{~Hz}$ & $1000 \mathrm{~Hz}$ & $5000 \mathrm{~Hz}$ & $10000 \mathrm{~Hz}$ & $20000 \mathrm{~Hz}$ \\
\hline Sample 1 & 0.0459 & 0.0180 & 0.0090 & 0.0181 & 0.0089 & 0.0091 \\
\hline Sample 2 & 0.0522 & 0.0255 & 0.0222 & 0.0202 & 0.0201 & 0.0198 \\
\hline Sample 3 & 0.0616 & 0.0554 & 0.0500 & 0.0487 & 0.0422 & 0.0387 \\
\hline Sample 4 & 0.0723 & 0.0621 & 0.0567 & 0.0534 & 0.0534 & 0.0501 \\
\hline Sample 5 & 0.0810 & 0.0711 & 0.0654 & 0.0613 & 0.0590 & 0.0532 \\
\hline Sample 6 & 0.0820 & 0.0760 & 0.0680 & 0.0659 & 0.0609 & 0.0588 \\
\hline
\end{tabular}

Table 6

THE DIELECTRIC DISSIPATION FACTOR FOR THE SAMPLES OF POM EUROTAL C9 NAT PROCESSED BY INJECTION, IN RELATION TO THE PERCENTAGE OF GRIINDING INCLUDED, AT DIFFERENT FREQUENCIES

\begin{tabular}{|c|c|c|c|c|c|c|}
\hline \multirow[t]{2}{*}{ Sample } & \multicolumn{6}{|c|}{ The dielectric dissipation factor $\operatorname{tg} \delta$ in relation to the measurement frequency } \\
\hline & $200 \mathrm{~Hz}$ & $500 \mathrm{~Hz}$ & $1000 \mathrm{~Hz}$ & $5000 \mathrm{~Hz}$ & $10000 \mathrm{~Hz}$ & $20000 \mathrm{~Hz}$ \\
\hline Sample 1 & 0.0476 & 0.0192 & 0.0095 & 0.0192 & 0.0095 & 0.0048 \\
\hline Sample 2 & 0.0468 & 0.0187 & 0.0093 & 0.0188 & 0.0094 & 0.0047 \\
\hline Sample 3 & 0.0465 & 0.0187 & 0.0093 & 0.0188 & 0.0093 & 0.0047 \\
\hline Sample 4 & 0.0470 & 0.0190 & 0.0095 & 0.0190 & 0.0094 & 0.0047 \\
\hline Sample 5 & 0.0468 & 0.0186 & 0.0093 & 0.0187 & 0.0093 & 0.0047 \\
\hline Sample 6 & 0.0473 & 0.0190 & 0.0095 & 0.0190 & 0.0095 & 0.0046 \\
\hline
\end{tabular}

Table 7

THE DIELECTRIC DISSIPATION FACTOR FOR THE SAMPLES OF ABS

MAGNUM 3453,

PROCESSED BY INJECTION, IN RELATION TO THE PERCENTAGE OF GRINDING INCLUDED, AT DIFFERENT FREQUENCIES
0.0061 , was recorded in sample 1 , at the frequency of $20000 \mathrm{~Hz}$.

After testing the samples of POM, the following results were obtained for the dielectric dissipation factor (table 6).

For the samples of polyoxymethylene tested is has been observed that increasing the percentage of grinding in samples, from 0 to $100 \%$, leads to a slight increase in the dielectric dissipation factor, i.e. reusing grinding in combination with new material leads to a slight increase in the dielectric dissipation factor of the manufactured object. This behavior applies to all measurement frequencies. Increasing the measurement frequencies, at each sample tested, results in a decrease of the dielectric dissipation factor. The highest value of the dielectric dissipation factor, of 0.0820 , was measured at sample 6 , at the frequency of $200 \mathrm{~Hz}$, while the lowest value, of 0.0089 , was recorded in sample 1 , at the frequency of $10000 \mathrm{~Hz}$.

After testing of the ABS samples, the following results were obtained for the dielectric dissipation factor (table 7).

For the samples of acrylonitrile butadiene styrene tested, it has been observed that increasing the percentage of grinding in samples, from $0 \%$ to $100 \%$, leads to insignificant changes in the values of the dielectric dissipation factor. This behavior applies to all measurement frequencies. Increasing the measurement frequencies, in the case of each sample tested, results in a decrease in the values of the dielectric dissipation factor. The highest value of the dielectric dissipation factor, of 0.0476 , was measured at sample 1, at the frequency of $200 \mathrm{~Hz}$, while the lowest value, of 0.0046 , was registered at sample 6 , at the frequency of $20000 \mathrm{~Hz}$.

In conclusion, it can be said that increasing the percentage of grinding in samples, from 0 to $100 \%$, leads to a slight increase in the values of the dielectric dissipation factor, in the cases of polyamide and polyoxymethylene, while in the case of acrylonitrile butadiene styrene, increasing the percentage of grinding in samples leads to insignificant changes. Increasing measurement frequencies for the three tested polymers results in a decrease of the values for the dielectric dissipation factor.

The graphic representations of the variation of relative permittivity in relation to the measurement frequency, for the three polymers studied, are presented in figure 9.

From the graphic representations shown in figure 9 , it can be concluded that increasing the measurement frequency for acrylonitrile butadiene styrene and polyoxymethylenes leads to insignificant changes in the values of relative permittivity while for polyamide increasing measurement frequency results in a slight decrease in the values of relative permittivity.

The graphic representations of the variation in dielectric dissipation factor ( $\operatorname{tg} \delta$ ) depending on the measurement 
frequency, in the case of the three polymers studied, are shown in figure 10.

The graphic representation in figure 10 shows that, for the three polymers analyzed (PA 6.6, POM and ABS), increasing the measurement frequency, from the value of $200 \mathrm{~Hz}$ to the value of $20000 \mathrm{~Hz}$, leads to a significant decrease of the dielectric dissipation factor.
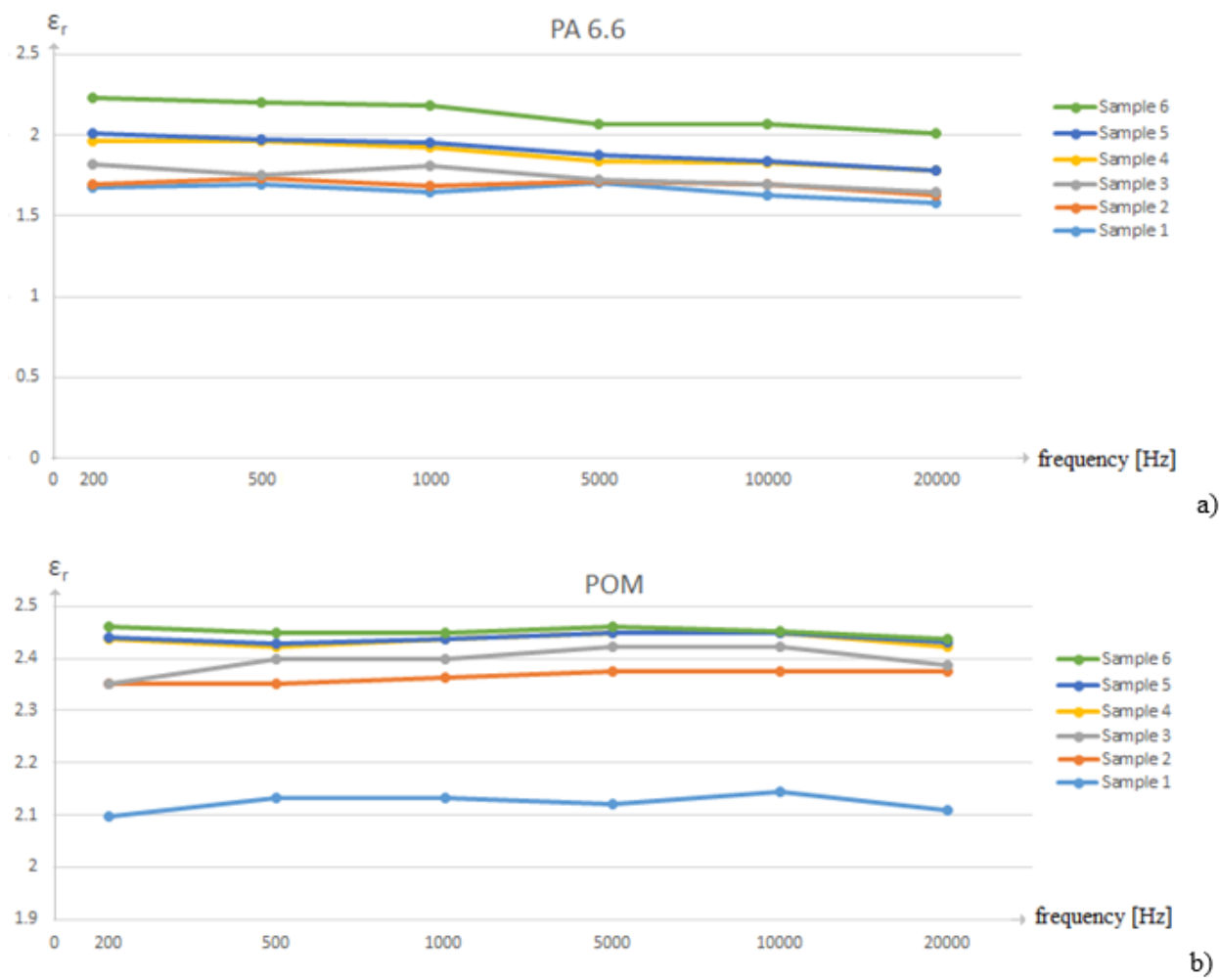

Fig.9. The variation of relative permittivity $\left(\varepsilon_{r}\right)$ depending on the measurement frequency at PA 6.6 (a), POM (b) and ABS (c)
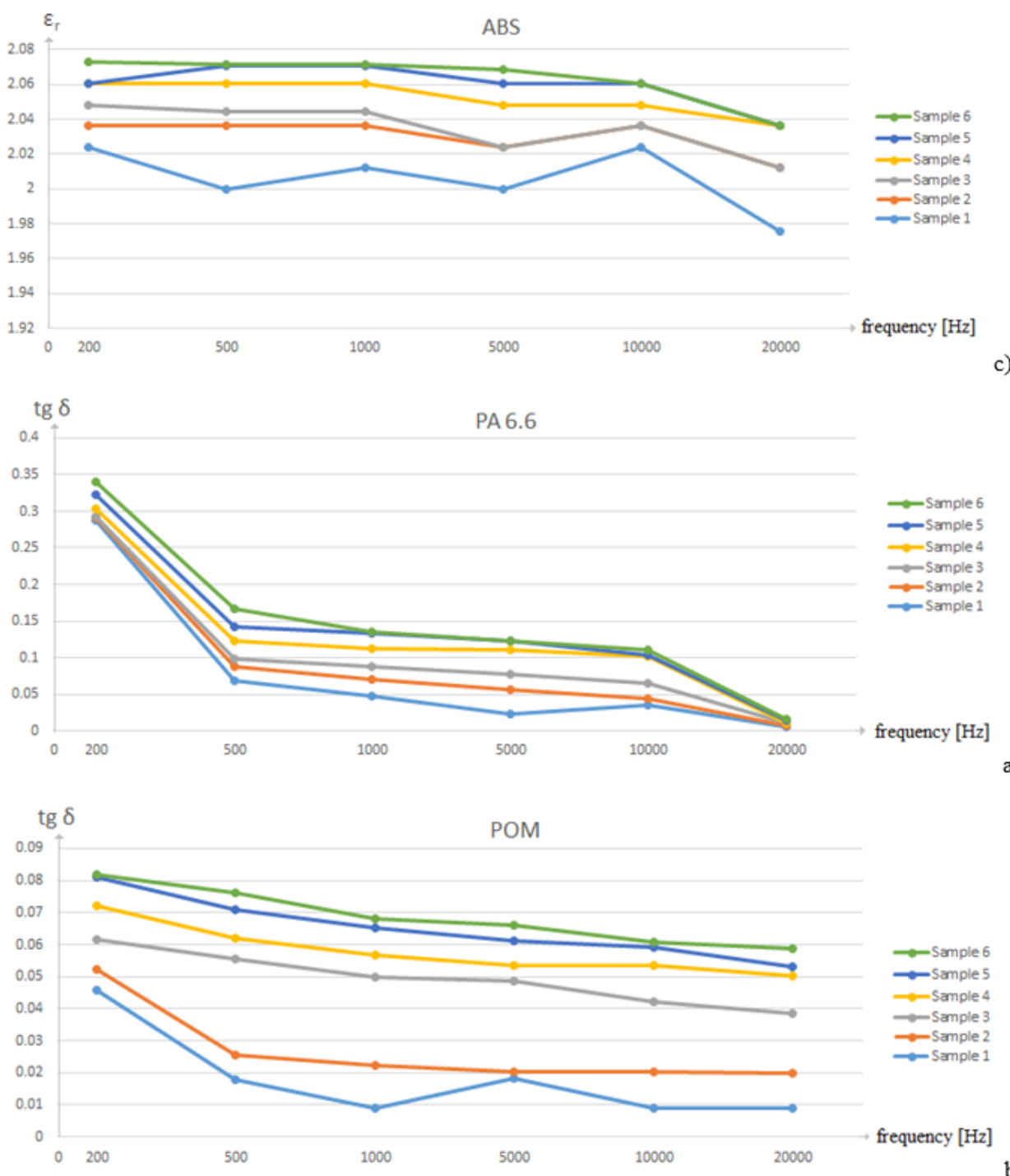

Fig.10. The variation of the dielectric dissipation factor ( $\operatorname{tg} \delta$ ) in relation to the measurement frequency at PA 6.6 (a), POM (b) 


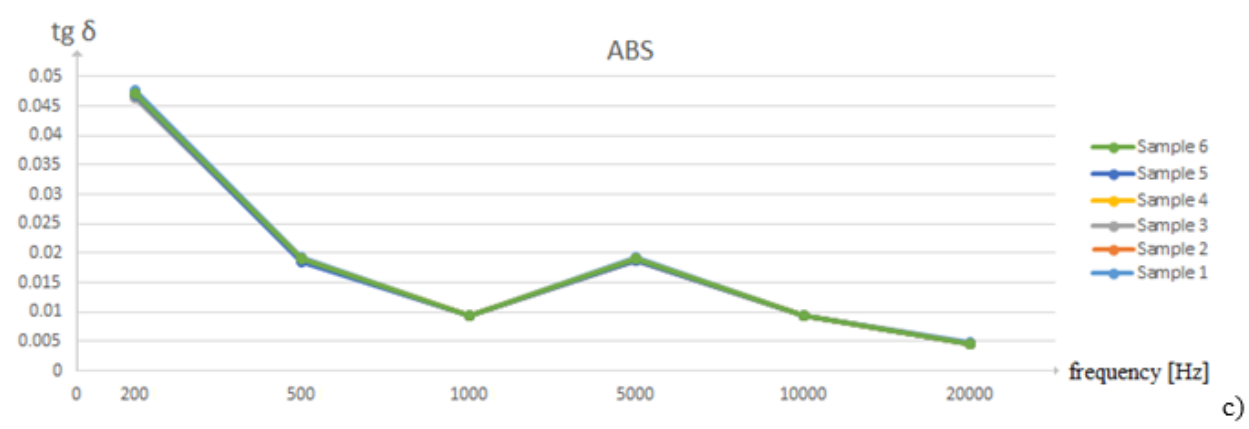

Fig.10. The variation of the dielectric dissipation factor

$(\operatorname{tg} \delta)$ in relation to the measurement frequency at $\mathrm{ABS}(\mathrm{c})$

\section{Conclusions}

We have studied changes of electrical properties, for varying percentages of grinding (polymer thermoformed by injection, one time only) in samples, and at different measurement frequencies, using methods for determining relative permittivity and the dielectric dissipation factor, with the help of the method of zero by Schering bridge, for PA 6.6 TECHNYL AR218V30 Blak polyamide type, the polyoxymethylene POM EUROTAL C9 AT and ABS MAGNUM 3453 NAT, which in this case are materials used in the manufacturing process of technical articles. The specimens made had the following compositions: new material $100 \%$, new material $80 \%$ + grinding $20 \%$, new material $60 \%$ + grinding $40 \%$, new material $40 \%$ + grinding $60 \%$, new material $20 \%$ + grinding $80 \%$ and $100 \%$ grinding. The samples were injected on an injection machine ENGEL CC 100 Type ES 80/50 HL. The tests were performed using as measuring device a Hew lett-Packard Model 4276A and a Tektronix oscilloscope model MD03024.

It was noted that increasing the percentage of grinding in samples, from 0 to $100 \%$, leads to a slight increase in the values of relative permittivity, at all the three polymers tested, while increasing measurement frequencies for acrylonitrile butadiene styrene and Polyoxymethylenes leads to insignificant changes in the values of relative permittivity. Increasing the measurement frequency in the case of polyamide leads to a slight decrease in values of relative permittivity.

Increasing the proportion of grinding in the samples, from 0 to $100 \%$, leads to a slight increase in the values of the dielectric dissipation factor, in the case of polyamide and polyoxymethylene, while in the case of acrylonitrile butadiene styrene, increasing the proportion of grinding in samples results in insignificant changes. Increasing the measurement frequencies for the three tested polymers results in a decrease of values for the dielectric dissipation factor.

Acknowledgement: Sincere thanks to the following companies: Plastor SA Oradea and SC Plastic Crisana SRL, and to Institut Superieur d'Electronique and et du Numerique (ISEN), from the Catholic University of Lille, France, for the material and logistical support given to the University of Oradea during the period of research, which focused on the influence, determined by changing the percentage of grinding in samples and changing measurement frequencies, on the electrical properties of three techno polymers frequently used in the manufacturing of technical commodities in various industries.

\section{References}

1. MARIES, GH., R., E., Contribuii la studiul unor caracteristici fizice ale polimerilor, utilizabili în articole sportive de performanã, prin metode termice, Editura Politehnica, Timisoara, 2007, p.11-21.

2. TROTIGNON, J., P., VERDU, J., DOBRACGINSKY, A., PIPERAUD, M., Matieres Plastiques. Structures-proprietes, Mise en oeuvre, Normalisation, Editions Nathan, Paris, 1996, p.80-84.

3. MANOVICIU, V., MARIES, GH., R., E., Materiale compozite cu matrice organicã, Editura Universitatii din Oradea, Oradea, 2005, p.135-141.

4. MARSAVINA, L., CERNESCU, A., LINUL, E., SCURTU, D., CHIRITA,

C., Mat. Plast., 47, no.1, 2010, p.85.

5. SERES, I., Materiale termoplastice pentru injectare, tehnologie, încercãri, Editura Imprimeriei de Vest, Oradea, 2002, p.93

6. PICHON, J., F., Injection des matieres plastiques, Dunod, Paris, 2001, p.12.

7. MARIES, GH., R., E., MANOVICIU, I., BANDUR, G., RUSU, G., PODE, V., Mat. Plast., 44, no.4, 2007, p.289.

8. MARIES, GH., R., E., Mat. Plast., 47, no.2, 2010, p.244.

9. NEDELCU, D., FETECAU, C., CIOFU, C., MINDRU, D., Mat. Plast., 46, no.3, 2009, p.269.

10. MARIES, GH., R., E., CHIRA, D., Mat. Plast., 49, no.4, 2012, p.288.

11. MARIES, GH., R., E., MANOVICIU, I., BANDUR, G., RUSU, G., PODE, V., Mat. Plast., 46, no.1, 2009, p.58.

12. CHIRA, D., MARIES, GH., R., E., Mat. Plast., 49, no.3, 2012, p.204.

13. MARIES, GH., R., E., Mat. Plast., 51, no.4, 2014, p.410.

14. VAIDA, L., MOLDOVAN, L., LILE, I., E., TODOR, B., I., PORUMB, A., TIG, I., BRATU, D., C., Mat. Plast., 52, no..3, 2015, p.364.

15. SUAREZ, J., C., M., MANO, E., B., TAVARES, M., I., B., J. Appl. Polym. Sci, 78, Issue: 4, 2000, p.899.

16. LI, B., ZHANG, XL., ZHANG, Q., CHEN, F., FU, Q., J. Appl. Polym. Sci, 113, Issue: 2, 2009, p.1207.

17. STAN, F., Mat. Plast., 45, nr.1, 2008, p.8.

18. GHITA, E., GILLICH, G.,R., BORDEASU, I., VODA, M., TROI, C.,Mat. Plast., 44, no..2, 2007, p.158.

19. CURTU, I., MOTOC, D., L., Mat. Plast., 45, no.4, 2008, p.366.

20. LILE, I., E., FREIMAN, P., C., HOSSZU, T., VASCA, E., VASCA, V., BUNGAU, S., VAIDA, L., Mat. Plast., 52, no.2, 2015, p.175.

21. MANZUR, A., OLAYO, R., RAMOS, E., J. Appl. Polym. Sci, 65, Issue: 4, 1997, p.677.

22. SUAREZ, J.,C.,M., MANO, E., B., MONTEIRO, E., E., D., TAVARES,

M., I., R., J. Appl. Polym. Sci, 85, Issue: 4, 2002, p.886.

23. VODA, M., BORDEASU, I., MESMACQUE, G., CHITAC, V., TABARA, I., Mat. Plast., 44, no.3, 2007, p.254.

24. GURUPRASAD, B., RAGUPATHY, A., BADRINARAYANAN, T., S., VENKATESAN, R., IJET, 2, nr.12, 2012, p.1921.

25. MARIES, GH., R., E., CHIRA, D., NOVAC, O., SIRGHIE, C., CHAMBRE, D., R., Mat. Plast., 53, no.3, 2016, p.458.

26. CHIRA, D., MÃRIES, GH., R., E., BUNGAU, C., Mat. Plast., 52, no. 4, 2015, p.572.

27. MARIES, GH., R., E., CHIRA, D., BUNGAU, C., Mat. Plast., 52, no.4, 2015, p. 452.

28. MARIES, GH., R., E., Mat. Plast., 52, no.1, 2015, p.32.

29. BARZIC, A., I., BARZIC, R., F., ZELINSCHI, C., B., Mat. Plast., 52, nr.1, 2015, p. 79 .

30. *** NF C 26-230:1970 CEI IEC 60250, METHODES D'ESSAI DES MATIERES ISOLANTES. Methodes recommandees pour la determination de la permittivite et du facteur de dissipation des isolants electriques aux frequences industrielles, audibles et radioelectriques (ondes metriques comprises)

$\overline{\text { Manuscript received: } 24.02 .2017}$ 